\title{
PROFESIONALISME JURNALIS LULUSAN JURUSAN JURNALISTIK UIN ALAUDDIN MAKASSAR
}

\author{
Oleh: Andi Fauziah Astrid \\ Jurusan Jurnalistik FDK UIN Alauddin Makassar \\ Fauziah.astrid@uin-alauddin.ac.id
}

\begin{abstract}
Abstrak
Profesionalisme seseorang biasanya diukur dari kemampuan kerja dan kepatuhan terhadap kode etik dan kemampuan menerapkan poin kompetensi sesuai bidang. Seorang jurnalis juga dituntut hal yang sama dalam bekerja. Dua poin utama yang harus dimiliki seorang jurnalis yaitu pematuhan terhadap Kode Etik Jurnalistik dan Standar Kompetens Jurnalis. Hal yang sama berlaku bagi lulusan Jurusan Jurnalistik UIN Alauddin Makassar. Sekalipun mereka menimba ilmunya secara langsung, tetapi pengalaman dan proses kerja yang membentuk profesionalisme yang mereka miliki.
\end{abstract}

Keyword : profesionalisme, jurnalis, jurusan jurnalistik

\section{A. PENDAHULUAN}

Sebuah pekerjaan menjadi baik jika dilandasi profesionalitas. Apapun konteks pekerjaannya, profesionalisme menjadi poin penting untuk memberi kualitas dari apa yang dikerjakan. Pada situs wikipedia ${ }^{1}$ disebutkan ketika seseorang disebut profesional, dia harus profesional dalam bidangnya meskipun bukan merupakan anggota sebuah entitas yang didirikan secara sah. Mereka juga digaji dan melaksanakan tugas sesuai petunjuk pelaksanaan dan dan petunjuk teknis yang dibebankan kepada dia.

Islam juga mengatur profesionalitas kerja. Seperti yang diutarakan Prof. Dr. Rina Indiastuti, SE., MSIE dalam portal Unpad.ac.id ${ }^{2}$ menyebutkan sebuah hadist yang berbunyi : "Sesungguhnya Allah suka kepada hamba yang berkarya dan terampil dan siapa yang bersusah payah mencari nafkah untuk keluarga maka dia serupa dengan seorang mujahid di jalan Allah Azza Wajalla (H.R. Ahmad). Hadist ini ditafsirkan bahwa Allah menjanjikan manusia rezeki yang luas asalkan bekerja secara profesional dan cerdas melalui etos kerja yang tinggi. Etos sendiri, seperti yang diajarkan Rasulullah pada riwayat Al-Baihaqi dalam "syu'bul Iman" ada empat, yaitu bekerja secara halal, bekerja demi menjaga diri supaya

\footnotetext{
${ }^{1}$ https://id.wikipedia.org/wiki/Profesional diakses 20 Maret 2018

${ }^{2}$ http://www.unpad.ac.id/rubrik/bekerja-profesional-dan-cerdas-menurut-islam diakses 20 Maret 2018
} 
tidak menjadi beban hidup orang lain, bekerja demi mencukupi kebutuhan keluarga, dan bekerja untuk meringankan hidup tetangga.

Salah satu pekerjaan yang membutuhkan profesionalitas yaitu jurnalis. Hal ini tertuang dalam beberapa aturan dan juga kode etik yang mengatur pekerjaan seorang jurnalis. Ketua Dewan Pers, Yosep 'Stanley' Adi Prasetyo dalam sebuah kesempatan, pernah mengingatkan para jurnalis untuk selalu bekerja secara profesional. Salah satunya, dengan mematuhi Kode Etik Jurnalistik sehingga berita yang dipublikasikannya dapat menjadi sumber informasi yang dapat dipercaya masyarakat. ${ }^{3}$ Selain itu, jurnalis juga wajib memiliki sertifikat uji kompetensi yang didapatnya setelah mengikuti uji kompetensi. Selain uji kompetensi, sebenarnya para jurnalis juga telah mendapatkan dukungan terhadap cara bekerja secara profesional, ketika mereka berada di bangku kuliah.

Seperti halnya, alumni yang berasal dari Jurusan Jurnalistik Fakultas Dakwah UIN Alauddin Makassar. Para alumnus ini, telah dibekali pengetahuan jurnalistik untuk mendukung cara bekerja, cara bertindak, dan cara bersikap dalam bekerja sebagai jurnalis. Beberapa mata kuliah memang diarahkan untuk pembentukan kompetensi kerja. Data yang tertera pada buku profil jurusan menyebutkan penetapan rumusan Profil Jurusan yang meliputi Kompetensi Utama dan Kompetensi tambahan yang merupakan hasil dari amanat Peraturan Presiden Republik Indonesia No. 8 Tahun 2012, tentang Kerangka Kualifikasi Nasional Indonesia (KKNI).

Jurusan yang memiliki visi 'Menjadikan Program Studi Jurnalistik sebagai pusat kajian Jurnalistik Islami yang profesional tahun 2025', tidak hanya mendorong para alumnus untuk menjadi profesional di bidang jurnalis tetapi mengayomi nilai-nilai islam. Beberapa mata kuliah yang menjadi unggulan dan sokongan profesionalitas kerja, di antaranya yaitu Dasar-dasar Broadcasting, Etika Jurnalis Islam, Jurnalistik Online, Jurnalistik Siaran, Teknik Peliputan, dan Bahasa Jurnalistik. ${ }^{4}$

Masalahnya, pekerjaan yang diburu deadline, terkadang membuat jurnalis abai terhadap sikap-sikap profesionalisme. Belum lagi, persaingan media massa yang menuntut para jurnalisnya untuk lebih cepat mengirimkan beritanya, terkadang memaksa jurnalis untuk menanggalkan apa yang telah mereka pelajari di bangku kuliah atau yang mereka

\footnotetext{
${ }^{3}$ http://dewanpers.or.id/berita/detail/879/Wartawan-Diajak-Tingkatkan-Profesionalitas diakses 20 Maret 2018

${ }^{4}$ Buku Profil Jurnalistik Tahun 2017
} 
dapatkan pada pelatihan-pelatihan jurnalistik. Akhirnya, bisa terjadi pelanggaran profesionalitas dalam kerja.

Fenomena ini membuat peneliti tertarik untuk mengkaji Profesionalisme Jurnalis Lulusan Jurusan Jurnalistik UIN Alauddin Makassar yang kemudian akan dikaitkan dengan Mutu Kurikulum Berbasis KKNI yang ada di jurusan Jurnalistik di Fakultas Dakwah dan Komunikasi UIN Alauddin Makassar.

\section{a. Rumusan Masalah dan Tujuan Penelitian}

\section{Rumusan Masalah}

Peneliti akan meneliti Profesionalisme Kerja Jurnalis Lulusan Jurusan Jurnalistik UIN Alauddin Makassar; Telaah Mutu Kurikulum Berbasis KKNI. Berdasarkan uraian pada latarbelakang masalah, maka peneliti merumuskan beberapa masalah dalam penelitian ini. Adapun paparannya sebagai berikut :

1. Bagaimana penerapan profesionalisme kerja jurnalis lulusan Jurusan Jurnalistik UIN Alauddin Makassar?

2. Bagaimana pemanfaatan kurikulum jurusan jurnalistik dalam meningkatkan profesionalitas kerja jurnalis lulusan Jurusan Jurnalistik UIN Alauddin Makassar?

\section{Tujuan Penelitian}

Sesuai dengan rumusan masalah yang telah diajukan peneliti, maka tujuan penelitian ini antara lain:

1. Untuk mendeskripsikan penerapan profesionalisme kerja jurnalis lulusan Jurusan Jurnalistik UIN Alauddin Makassar.

2. Untuk mendeskripsikan pemanfaatan kurikulum jurusan jurnalistik dalam meningkatkan profesionalitas kerja jurnalis lulusan Jurusan Jurnalistik UIN Alauddin Makassar.

\section{b. Fokus Penelitian dan Deskripsi Fokus}

\section{Fokus Penelitian}

Fokus penelitian menjadi batasan penelitian supaya ruang lingkup yang akan diteliti menjadi jelas. Fokus penelitian tidak hanya digunakan untuk mengungkapkan sesuatu 
yang dilihat dari luarnya saja, tetapi harus menyentuh persoalan pada bagian-bagian tertentu yang ada pada subjek penelitian. Batasan penelitian ini pada profesionalisme kerja jurnalis yang merupakan alumni jurusan jurnalistik.

\section{Deskripsi Fokus}

Topik penelitian ini tentang "Profesionalisme Kerja Jurnalis Lulusan Jurusan Jurnalistik UIN Alauddin Makassar; Telaah Mutu Kurikulum Berbasis KKNI. Maka, untuk menghindari kesalahpahaman, terlebih dahulu penulis memberikan pengertian mengenai topik tersebut, yaitu :

a. Profesionalisme kerja jurnalis, yaitu cara bekerja seseorang yang berdasarkan standar-standar jurnalistik, standar kompetensi, dan kode etik jurnalistik.

b. Jurnalistik yaitu proses mencari, mengumpulkan,dan menulis fakta data yang ada di lapangan dan menuangkannya di media massa.

c. Standar Kompetensi jurnalis yaitu menyangkut kemampuan yang harus dimiliki seorang jurnalis untuk melakukan tugasnya didasari atas pengetahuan, keterampilan, dan sikap kerja.

d. Kode etik jurnalistik yaitu kode etik yang dikeluarkan Dewan Pers untuk mengatur etika jurnalis.

e. Lulusan/alumni yaitu orang yang telah meyelesaikan proses perkuliahan dan mendapatkan ijazah (sarjana).

Standar mutu kurikulum berbasis KKNI yaitu acuan kualitas kurikulum atau mata kuliah yang diintegrasikan dengan KKNI atau kerangka kualifikasi nasional Indonesia.

\section{B. Pembahasan}

Profesionalisme jurnalis menjadi salah satu pemenuhan kualitas kerja seseorang di bidang jurnalistik memerlukan keahlian, kemahiran, ataupun kecakapan sesuai standar mutu tertentu yang diperoleh melalui pendidikan dan pengalaman profesi. Pendekatan ini dibuat untuk membantu jurnalis mengembangkan potensinya lebih optimal dalam bekerja.

1. Penerapan profesionalisme kerja jurnalis lulusan Jurusan Jurnalistik UIN Alauddin Makassar. 
Peneliti melakukan wawancara kepada lima orang alumnus Jurusan Jurnalistik UIN Alauddin Makassar. Yaitu Mardianto dari Celebes TV, Nila Rustam dari Kompas TV, Indra Ahmad Firdaus dari Harian Go Cakrawala, Muhammad Alfath Triawan fotografer di Harian Saudagar Makassar, dan Juminah dari Harian Saudagar.

Peneliti melihat bahwa Kode Etik Jurnalistik yang mereka pahami pada umumnya sudah baik. Walaupun tidak bisa dilaksanakan secara keseluruhan. Para informan menghargai ketentuan off the record narasumber, merekam setiap hasil wawancara, melakukan hak jawab, memberitakan sesuai fakta, menghargai kerahasiaan identitas narasumber. Pada dasarnya, kelima informan mengetahui kode etik dasar jurnalistik. Namun pada konteks menerima gratifikasi, beberapa informan masih belum dapat menerapkan secara menyeluruh. Seperti yang disampaikan oleh Mardianto. Ia menuturkan jika ia tidak merasa nyaman jika menolak pemberian narasumber, karena memiliki kedekatan emosional, sehingga dirinya mau tidak mau akan mengambil atau menerima gratifikasi tersebut.

"Kadang-kadang kita tidak mau menerima tapi secara emosional karena kita punya kedekatan dengan orang itu. Jadi kita menganggap itu bukan gratifikasi.misalnya saya dekat dengan narsum terus setelah saya wawancarai dia ajak makan, karena tidak enak jadi saya iyakan saja atau biasanya dia kasih tip, kadangkadang tidak enak juga kalau ditolak. Tapi lebih besar kita tidak ambil, apalagi kalau orang itu saya tidak memiliki kedekatan, tapi saya tidak menafikkan." ${ }^{5}$

Untuk konteks melakukan pencabutan berita juga pernah dialami oleh Mardianto, dalam pengalamannya seorang narasumber memintanya menarik berita video yang telah disiarkan. Pencabutan berita tidak serta merta dapat dilakukan langsung, karena mengikuti kebijakan perusahaan. Namun, dalam hal ini tetap memberikan ruang bagi para narasumber untuk melakukan hak jawab atau klarifikasi berita.

"Kecuali memberikan hak jawab atau klarifikasi, karena kalau di TV itu sudah tayang tidak mungkin bisa ditarik kembali. Karena memungkinkan muncul kesan publik. Tidak pernah terjadi, tapi ada yg pernah komplain itu minta ditarik. Tapi kami punya independensi kalau itu tidak bisa ditarik. Kita punya aturan sendiri di media." 6

\footnotetext{
${ }^{5}$ Jurnalis Celebes TV Makassar.
}

${ }^{6}$ Mardianto, Jurnalis Celebes TV 
Pada etik melindungi narasumber, jurnalis lulusan UIN Alauddin telah mengetahui dan menghargai keputusan narasumber ketika memberitahukan informasi penting, namun mengatakan off the record. Seperti yang dirasakan Nila Rustam Jurnalis video di Kompas TV. Ia menuturkan untuk tetap tidak memberitakan wawancara off the record meskipun informasi tersebut sangat penting diketahui publik.

"Biasanya kalau seperti itu, tetap tidak dibuat. Walaupun kita buat, paling kita di lingkup yang on record, kalau off the record pasti tidak.karena memang dalam aturannya kalau memang tidak bisa ya tidak bisa." 7

Profesonalisme kerja juga berhubungan standar kompetensi Wartawan. Dari hasil wawancara yang telah dilakukan penulis, secara umum kelima informan memenuhi Standar Kompetensi Jurnalis jenjang Muda. Ini tergantung dari kebijakan perusahaan yang mempekerjakan masing-masing jurnalis seperti mengikuti rapat redaksi, memberikan masukan ide atau agenda pemberitaan, menemui langsung narasumber, bertanya dengan standar dasar $5 \mathrm{~W}+1 \mathrm{H}$, menyimpan kontak narasumber, hingga melakukan proses membuat dan mengirim berita menggunakan teknologi surel elektronik (email) atau alat pelengkap lainnya.

Seperti dalam hal mengikuti rapat redaksi, Secara umum, kelima informan mengikuti rapat redaksi sesuai dengan kebijakan di perusahaan tempat mereka bekerja. Rapat redaksi yang dimaksud untuk mengagendakan topik pemberitaan setiap hari. Juminah yang kini menjadi editor pemberitaan di Harian Saudagar menjabarkan kegiatannya mulai dari penentuan tema berita bersama para redaktur lain, mengusulkan berita, sampai pada membagikan tugas pada masing-masing jurnalis di lapangan.

"Bisa juga dari reporternya. Setelah itu, ditentukan kita akan mengangkat berita apa besoknya. Termasuk misalnya ini tema, narsum, dan anglenya lalu nanti dikembangkan." 8

Berbeda dengan yang dialami Indra Ahmad Firdaus jurnalis Harian Go Cakrawala yang justru tidak pernah melakukan rapat redaksi secara langsung dengan

\footnotetext{
${ }^{7}$ Nila Rustam, Jurnais Kompas TV

${ }^{8}$ Juminah, Jurnalis Harian Saudagar
} 
para karyawan. Penggunaan media sosial seperti Whatsapp menjadi ruang rapat membahas agenda topik berita.

"Rapat itu hanya satu dua kali saja selama ini. Saya lebih jarang ke kantor, koordinasinya lebih sering di grup penugasan dan sebagainya, termasuk bahan liputannya seperti apa." 9

Sebagai seorang jurnalis yang bertugas di lapangan, Indra menuturkan sering diberi kesempatan untuk mengusulkan ide atau topik berita. Hasil wawancara pada kelima informan juga mengatakan memberikan masukan ide dan agenda berita.

"Saya agak jarang ikut rapat. Rapat itu hanya satu dua kali saja selama ini. Saya lebih jarang ke kantor, koordinasinya lebih sering di grup penugasan dan sebagainya, termasuk bahan liputannya seperti apa." ${ }^{10}$

Sementara Alfath yang bekerja sebagai fotografer, dalam rapat redaksi, ia akan melihat agenda kegiatan yang akan diliput lalu memilih berdasarkan kebutuhan gambar berita. Alfath juga tetap diberi kebebasan untuk mengusulkan gambar liputan, kemudian menunggu redaktur menyetujui gambar yang dipilihnya tersebut.

"Kita di sini apabila ada agenda yang menarik atau bagus. Seumpama kasus bencana, kita running setiap hari. Jadi koordinasi antara korlip, redaktur, sama pimred. Jadi Pemred bilang apa headline besok, jadi saya tawarkan gambar apa yang menarik. Kalau Pemred ACC maka akan dimuat."11

Hampir sama dengan tanggapan sampel lainnya, Mardianto juga diberi kebebasan dalam mengusulkan agenda liputan kemudian dipertimbangkan seberapa menarik untuk diberitakan ke publik.

"Seperti saya dulu di Pemprov memasukkan isu yang lagi hangat-hangatnya kemudian besok ditindaklanjuti," 12

Khusus peristiwa mendadak, para jurnalis yang lowong termasuk Mardianto akan diperintahkan untuk memberitakan di luar jobdesk atau wilayah liputannya.

Berbeda dengan Nila yang menjadi salah seorang jurnalis kontributor di Kompas TV Makassar. Rapat redaksi dilakukan hanya sekadar koordinasi melalui media sosial, dikarenakan banyak dari jurnalis Kompas TV yang berasal dari wilayah

\footnotetext{
${ }^{9}$ Indra Ahmad Firdaus Jurnalis Harian Go Cakrawala

${ }^{10}$ Indra Ahmad Firdaus Jurnalis Harian Go Cakrawala

${ }^{11}$ Alfath Triawan, Fotografer Harian Saudagar

12 Mardianto, Jurnalis Celebes TV
} 
jauh, ini juga sekaligus mengektivitaskan waktu liputan dimana mereka memiliki tugas lebih banyak dibandingkan jurnalis dari media lain.

"Karena ada beberapa di tempat di lokasi yang jauh misalnya di Polda, atau di lokasi yang tidak memungkinkan untuk kembali mengcopy gambar, jadi kalau liputannya jauh biasanya langsung dikirim dari sana. Terus kalau ada apa-apa biasa dibahas di grup." ${ }^{13}$

Untuk mengusulkan topik berita, Nila bersama jurnalis lainnya biasanya melaporkan topik pemberitaan di waktu sore sehari sebelumnya. Masing-masing jurnalis dipersilahkan memberikan usulan liputan.

"Kecuali kalau ada isu atau perintah dari kantor baru disetting memang dari kantor siapa saja yang akan ditugaskan." ${ }^{14}$

Profesionalisme juga diperlihatkan dari cara menemui dan mewawancarai narasumber. Pada tahap ini, hasil wawancara menunjukkan bahwa kelima informan menemui narasumber secara langsung untuk melakukan verifikasi data. Nila dan Mardianto yang merupakan jurnalis video menemui narasumber untuk konfimasi hasil berita. Muhammad Al-Fath Triawan jurnalis fotografer di Harian Saudagar menuturkan juga kadang-kadang melakukan wawacanra langsung pada narasumber meskipun pekerjaannya hanya sebagai fotografer.

"Karena kan kalau kita fotografer tidak panjang tulisannya seperti reporter yang bisa sampai tujuh atau delapan paragraf. Palingan empat yang penting lengkap di dalamnya," 15

Di setiap pertanyaan yang akan ditanyakan pada narasumber, hasil menunjukkan kelima informan jurnalis lulusan UIN Alauddin Makassar mengacu pada standar dasar $5 \mathrm{~W}+1 \mathrm{H}$. Setiap pertanyaan yang akan diajukan distruktur untuk menggiring jawaban yang diinginkan dari narasumber, dalam hal ini adalah agenda setting.

Setelah selesai wawancara, kelima informan menuturkan tetap meminta nomor kontak narasumber untuk tindak lanjut kebutuhan wawancara berikutnya. Namun

\footnotetext{
${ }^{13}$ Nila Rustam, Jurnalis Kompas TV

${ }^{14}$ Nila Rustam, Jurnalis Kompas TV

${ }^{15}$ Alfath Triawan, Fotografer Harian Saudagar
} 
menurut Juminah, selain untuk kebutuhan berita juga sebagai bentuk investasi jangka panjang di kemudian hari.

"Itu dipelihara karena saya yakin suatu saat mungkin saya bakalan minta bantuan dia." 16

Sementara Nila dan Mardianto menyimpan kontak narasumber untuk kebutuhan wawancara berikutnya, seperti sebagai narasumber untuk program talkshow khusus isu tertentu. Sementara Alfath justru berbeda, ia hanya meminta kontak dari pihak hubungan masyarakat (Humas) penyelenggara kegiatan yang ia potret.

"Biasanya saya lebih ke humasnya, karena kan humas minta hasil pemberitaan. Saya tidak langsung."17

Pada proses pembuatan berita, (mengacu pada standar kompetensi wartawan jenjang muda), proses pembuatan berita hingga dipublikasikan penting untuk diketahui para jurnalis. Dari kelima informan yang diwawancarai, semuanya telah mengetahui seperti apa proses memberitakan fakta.

Dimulai dari melihat kondisi di lapangan, konfirmasi dan wawancara narasumber, menulis naskah, menyortir gambar atau video, mengirim melalui surat elektronik, mengedit berita, hangga akhirnya dipublikasikan.

Di media cetak tempat Indra bekerja, mendapatkan informasi melalui sebaran rilis menjadi data awal sebelum langsung ke lapangan. Memanfaatkan hasil wawancara langsung ataupun melalui media sosial pada narasumber hanya mempertegas kebenaran data yang diberikan, lalu kemudian diolah dan dikirim langsung melalui surat elektronik untuk disunting oleh redaktur.

Lain dengan Juminah yang sudah menjadi editor tematik. Tugasnya tinggal menunggu hasil berita yang dikirimkan para jurnalis lapangan untuk disunting sebelum masuk ke tahap pencetakan. Jika belum melengkapi atau tidak sesuai dengan hasil berita, Juminah akan langsung melakukan wawancara kembali pada narasumber bersangkutan untuk mempertegas dan mengarahkan ke informasi yang dimaksud sekaligus membangun emosional kepada narasumber.

"Lebih enak ketemu langsung, datanya kurang tinggal sedikit, yang penting kalau saya itu dalam waancara ada hubungan emosional terbangun," 18

${ }^{17}$ Alfath Triawan, Fotografer Harian Saudagar 
Alfath yang juga bekerja di media cetak, juga seringkali melakukan penyortiran foto atau gambar sebelum diusulkan kepada redaktur. Dalam tugasnya, hasil foto kemudian diedit menggunakan aplikasi komputer untuk menajamkan hasil gambar. Lalu dikirim melalui surat elektronik.

Berbeda dengan Mardianto dan Nila yang sama-sama sebagai jurnalis tv. Tugas keduanya tidak jauh berbeda, yakni mengambil vidio kondisi di lapangan lalu mewawancarai narasumber. Sebagai jurnalis vidio kedua sampel ini melakukan kerja lebih dibandingkan jurnalis cetak maupun online.

Selain mengambil vidio, jurnalis tv juga dituntut untuk dapat membuat naskah narasi keterangan dalam vidio. Setelah gambar dan naskah selesai, proses sortir dan penyuntingan gambar seperti menghubungkan setiap vidio yang ada dan dibuatkan menjadi satu berita utuh sebelum diberikan kepada penyunting untuk dikoreksi kembali, hingga akhirnya berita dinyatakan layak untuk disiarkan.

Teknologi pendukung yang digunakan untuk mereka juga sangat berbeda. Jika Juminah dan Indra sebagai redaktur dan penulis hanya menggunakan telepon pintar (smartphone) atau komputer, Alfath menggunakan paralatan tambahan seperti kamera foto seperti Digital Single Lens Reflex (DCLR). Sementara Nila dan Mardianto menggunakan peralatan tambahan khusus video seperti cam recorder.

"Media yang digunakan untuk merekam adalah kamera Sony MC50, untuk ambil gambar, selanjutnya pakai laptop diedit menggunakan program Adobe Premiere setelah itu dikirim melalui filezilla ke KompasTV Jakarta." 19

\section{Pemanfaatan kurikulum jurusan jurnalistik dalam meningkatkan profesionalitas kerja jurnalis lulusan Jurusan Jurnalistik UIN Alauddin Makassar.}

Menentukan standar ajaran bagi para lulusan Jurnalistik UIN Alauddin Makassar, tidak sepenuhnya memenuhi ataupun sesuai sasaran untuk menunjang profesi mereka. Berdasarkan presentasi, kelima sampel mengaku kurikulum yang dapat diterapkan di lapangan hanya 5-30\%. Ini dikarenakan jurnalistik lebih melakukan praktik lapangan dibandingkan memahami teori akademik.

18 Juminah Harian Saudagar

${ }^{19}$ Nila Rustam, jurnalis Kompas TV 
Alfath yang sempat bertahan lama di lingkungan kampus mengaku menginginkan peranan praktik lebih banyak dibanding memahami lebih banyak teori. Ia bahkan hanya mendapatkan praktik dari luar lingkungan kampus.

"Kalau praktik itu kita cari di luar lagi, jarang dapat di dalam kampus. Adapun itu palingan kita disuruh keluar, anggaplah kita belajar ke Benteng tempat wisata wawancara lepas. Nanti tugasnya dikumpul lagi selesai itu tidak ada evaluasi. Harusnya akademik kalau memang mau menciptakan seorang jurnalis dari akademik.harus memang ada evaluasi."

Ini dikarenakan menurut Alfath, dosen pengampuh kurikulum yang ada belum semua berpengalaman pada bidang yang diajarkan. Bahkan, praktisi dalam mata kuliah bersangkutan hanya dapat dihitung jari. Sehingga penerapan antara akademik dan praktik masih sangat kurang.

"Dosen itu lebih bagus kalau memang dia mau mengajar di jurnalistik memang dia basicnya harus sesuai dengan jurnalistik. Kurang lebih pengalaman yah 5-10 tahun, karena kita bisa ada patokan pengajaran (kurikulum) apa yg sesuai kepada mahasiswa, atau pengalaman yg disampaikan ke mahasiswa." 21

Adapun mata kuliah yang dapat ia terapkan setelah bekerja di antaranya Fotografi, Broadcasting, Video jurnalistik, Penulisan jurnalistik, dan dasar-dasar komunikasi.

Alfath menyarankan agar akademik melibatkan kehadiran para lulusan ahli di bidangnya untuk turut memberikan kontribusi dalam proses mengajar kepada para mahasiswa sekaligus membangun koneksi antara senior dan junior mereka.

"Maksudnya kalau bisa alumni untuk pengembangan jurnalistik kalau bisa dimanfaatkan kan SDM-nya. Karena kan kedekatan antara senior dan junior lebih rekat daripada dosen ke mahasiswa." ${ }^{22}$

Berbeda dengan pengalaman dirasakan Indra yang justru lebih aktif dan mendapat ilmu lebih banyak ketika mengikuti organisasi kampus bidang jurnalistik. Dibandingkan mengikuti kurikulum kampus, Indra mengaku hanya 30-40\% ilmu akademik yang bisa ia terima. Bahkan berdasarkan pengalamannya, ketika pemberian materi pembelajaran belum tentu mengajarkan praktik langsung di lapangan. Bahkan, tak jarang meminta mahasiswanya mencari sendiri.

\footnotetext{
${ }^{20}$ Alfath Triawan, Fotografer Harian Saudagar

${ }^{21}$ Alfath Triawan, Fotografer harian Saudagar

${ }^{22}$ Alfath Triawan, Fotografer Harian Saudagar
} 
Menurut Indra, peran organisasi kejuruan justru sangat membantunya mengembangkan ilmu jurnalistik. Sementara penempatan dosen pengajar harus sesuai dengan mata kuliah yang diterapkan, agar semuanya dapat dimengerti.

"Kalau dibilang sesuai, sesuai. Cuman masih ada beberapa dosen yang bisa dibilang mengajar tapi keilmuannya bukan di situ. Itu yang kadang saya salah tanggap." 23

Kurikum keilmuan yang dapat diterapkan Indra antara lain Dasar Broadcasting, Bahasa Jurnalistik, Jurnalistik Siaran, Komunikasi Pembanguan, Tehnik Peliputan dan Penulisan Berita, Foto Jurnalistik, dan Investigasi Reporting.

Mardianto justru memprentasekan akademik diterapkan di lapangan hanya sekitar 20\%, ilmu yang diberikan rata-rata hanya pengantar. Ini menurutnya kurang efektif, karena menurutnya dosen pengampuh tidak memberikan ilmu secara merinci, ada juga dosen yang katanya hanya memberikan teori dan praktik namun tidak sesuai.

"Apa yg diajarkan di kampus dan di lapangan itu kaku sehingga tidak sama kalau kita di lapangan," 24

Selain itu, pemberian teori di lingkungan kampus tidak besar dalam memberikan peran besar pada praktik yang diberikan menurut Mardianto, mengingat apa yang didapatkan tidak signifikan antara kajian keagamaan dengan penerapan jurnalistik secara umum.

"Otomatis apa yang didapatkan di kampus tidak terlalu diaplikasikan. Adapun itu kadang-kadang kalau liputan keagamaan itu baru dilibatkan. Tapi kalau secara garis besar itu penting atau tidak, saya pikir itu tidak terlalu signifikan," 25

Mardianto menyarankan sebaiknya mata kuliah yang diberikan mengikuti perkembangan dunia jurnalistik. Agar para lulusan nantinya bekerja sebagai jurnalis tidak kaku dan kaget ketika berada di lapangan melihat apa yang ada di lingkungan kampus sangat berbeda dengan penerapan di lapangan dan menganggap jurnalistik menjadi hal baru.

"Seperti misalnya perlu penekanan matkul kode etik jurnalistik supaya tidak kaget melihat sesuatu yang lain-lain. Terus teknik penulisan berita yang perlu

\footnotetext{
${ }^{23}$ Indra, Harian Go Cakrawala

${ }^{24}$ Mardianto, Jurnalis Celebes TV

${ }^{25}$ Mardianto, Celebes TV
} 
ditekankan lebih lagi, Karena apa yang disampaikan narsum tidak relevan dengan hasil berita yang dihasilkan berbeda, sehingga narsum tidak komplain." ${ }^{26}$

Adapun kurikulum yang menurutnya penting dalam penerapannya di lapangan antara lain Etika Jurnalis Islam, Jurnalistik Siaran, Komunikasi Antar Pribadi dan Budaya, Komunikasi Massa, Penulisan Kreatif, Psikologi Komunikasi, Penelitian Jurnalistik, Produksi dan Industri Media, Produksi siaran dan Media tv, Radio dan Presentasi, Fotografi dan Foto Jurnalistik, serta Teknik Peliputan dan Penulisan Berita.

Berbeda dengan yang dialami Nila, ia justru menyayangkan ruang praktik kampus tidak dipergunakan baik untuk para mahasiswa ketika masih kuliah dulu. Pengalaman praktik mengoperasikan alat justru ia dapatkan setelah bekerja. Akademik yang ia dapatkan di lingkungan kampus lebih kepada memberikan ilmu agama, sementara materi yang betul-betul fokus pada jurnalistik baru ia dapatkan setelah berada di semester enam dan tujuh saat akan menyusun skripsi dan waktu magang di perusahaan. Khusus penggunaan alat, menurutnya hanya pada saat ketika mahasiswa mengikuti organisasi dan orang tertentu saja yang dapat menggunakan peralatan untuk praktik siaran.

"Untuk kamera juga kemarin kita tidak sempat masuk ke laboratorium lantai 4. Tidak ada juga akses ke sana. Sementara radio bagi mereka yang mendaftar saja yang boleh masuk. Karena katanya masih baru, jadi masih minim dosen yang basic ilmunya ke sana." ${ }^{27}$

Berdasarkan pengalaman yang dialami Nila, ia hanya dapat mempresentasikan $10 \%$ ilmu didapatkannya di dalam penerapan akademik saat di lapangan. Ilmu siaran dan proses pembuatan berita baru ia dapatkan, murni setelah ia bekerja di perusahaan. Sehingga kurikulum mata kuliah yang ia terapkan hanya seperti Pengantar Ilmu Komunikasi, Psikologi, Bahasa Jurnalistik, dan Komunikasi Massar.

Nila menyarankan agar penerapan jurusan ilmu komunikasi menggunakan perbandingan antara $30 \%$ teori dan $70 \%$ praktik, karena teori dan apa yang ada di lapangan bisa saja berbeda. Sebisa mungkin praktik diberikan sejak awal perkuliahan, jangan menunggu hingga akhir semester saat penelitian akhir.

\footnotetext{
${ }^{26}$ Mardianto, Celebes TV

${ }^{27}$ Nila Rustam, Kompas TV
} 
"Jadi pada saat mereka magang akan betul-betul $100 \%$ baru melihat peralatan. Jadi kalau misalnya peralatan yang ada di studio tidak dipergunakan dengan baik, sama saja nol. Kalaupun rusak karena pemakaian itu masih lebih bagus dari pada rusah karena tinggal tidak dipergunakan." 28

Persentasi penerapan ilmu jurnalistik akademik Juminah justru lebih sedikit dibandingkan dengan sampel lainnya. Juminah menuturkan hanya menerima 5\% setelah bekerja di media. Ia lebih termotivasi melakukan kunjungan ke media dibandingkan mengikuti kuliah. Bahkan ilmu praktik jauh lebih banyak didapatkannya setelah mengikuti organisasi jurnalistik kampus seperti Wasila.

"Bayangkan saya kuliah 3,5 tahun ada yang 4 tahun atau 5 tahun. Tapi itu tidak menjamin mereka bisa menulis. Yang salah apa? Karena kita hanya diberi teori, padahal jurnalis adalah ilmu praktik. Harusnya tiap hari kau menulis. Itu saja, tidak usah banyak teori. Seandainya saya tidak bergabung di UKM seperti lima wasila, flash, senior-senior mengajarkan kami menulis, mengajarkan nilai berita, mengajarkan praktik tiap hari, pasti saya tidak akan bisa menulis. Saya pasti malu." ${ }^{29}$

Menurut Juminah, kurikulum baiknya diganti untuk menciptakan lulusan jurnalistik berkualitas agar nantinya profesi jurnalis tidak disepelekan oleh orang lain.

"Buktinya, banyak jurnalis yang backgroundnya bukan dari jurnalistik. Nah, itu PRnya apa yang membedakan nanti jurusan jurnalistik sama jurusan lain. Kita loh tidak bisa jadi advokad, tapi mereka bisa jadi jurnalis." ${ }^{30}$

Adapun kurikulum yang diterapkan Juminah antara lain Bahasa Jurnalistik, Jurnalistik Online, Etika Jurnalis Islam, Penulisan Kreatif, Investigasi Reporting, Produksi dan Industri Media, Promosi Periklanan, Radio TV Presenting, Fotografi dan foto Jurnalistik, Grafika dan Penerbitan, juga Teknik Peliputan dan Penulisan Berita.

\section{Kesimpulan dan Implikasi}

Profesionalime Jurnalis Lulusan Jurusan Jurnalistik UIN Alauddin Makassar pada lima informan merupakan penelitian yang kualitatif dengan model deskriptif. Sebagai penelitian kualitatif, penelitian ini bertujuan untuk memaparkan profesionalisme jurnalis

\footnotetext{
${ }^{28}$ Nila Rustam, Kompas TV

${ }^{29}$ Juminah, Harian Saudagar

${ }^{30}$ Juminah, Harian Saudagar
} 
yang dikaitkan dengan Kode Etik Jurnalis dan Standar Kompetensi Wartawan tingkat Muda.

1. Penerapan profesionalisme kerja jurnalis lulusan Jurusan Jurnalistik UIN Alauddin Makassar sudah mulai maksimal. Hanya saja, masih ada beberapa yang belum sepenuhnya patuh pada kode etik, misalnya menerima gratifikasi atau tip dari narasumber yang harusnya tidak boleh.

2. Pemanfaatan kurikulum jurusan jurnalistik dalam meningkatkan profesionalitas jurnalis lulusan Jurusan Jurnalistik UIN Alauddin Makassar dirasakan kelima informan masih sangat jauh. Mereka hanya bisa mendapatkan sekitar 20-30 persen manfaat dari mata kuliah yang selama ini mereka dapatkan. Untuk itu, mereka menyarankan ada perubahan kurikulum yang berbasis kompetensi.

\section{Daftar Pustaka}

Atmakusumah. 2000.10 Pelajaran untuk Wartawan. Jakarta : LSPP dan UNESCO Bujono, Bambang dan Toriq Hadad. 1996. Seandainya Saya Wartawan Tempo. Jakarta : ISAI dan Yayasan Alumni Tempo

Bulaeng, Andi. 2002. Teori dan Manajemen Riset Komunikasi. Jakarta : Penerbit Narendra Cangara, Hafied. 2012. Pengantar Ilmu Komunikasi. Jakarta : PT Raja Grafindo Persada Iskandar, Maskun dan Atmakusumah. 2006. Panduan Jurnalistik Praktis. Jakarta :LPDS-FES Gaines, William C. 2007. Laporan Investigasi untuk Media Cetak dan Siaran, Edisi Bahasa Indonesia. Jakarta : ISAI-Kedutaan Besar Amerika Serikat

Kovach, Bill dan Tom Rosentiel. 2012. Blur.Jakarta : Dewan Pers Luwarso,Lukas dan Atmakusumah.2001. Menegakkan Etika Pers. Jakarta : Dewan Pers Muis, A. 2001. Komunikasi Islami. Bandung : PT Remaja Rosdakarya --------.1999. Jurnalistik Hukum Komunikasi Massa. Jakarta : PT Dharu Anuttama Nazir, Moh. 2005. Metode Penelitian. Bogor : Ghalia Indonesia Nurudin. 2007. Pengantar Komunikasi Massa. Jakarta : PT RajaGrafindo Persada ---------. 2017. Perkembangan Teknologi Komunikasi. Jakarta : PT RajaGrafindo Persada Pujileksono, Sugeng. 2016. Metode Penelitian Komunikasi Kualitatif. Malang : Kelompok Intrans Publishing

Sukardi, Wina Armada. 2010. Standar Kompetensi Wartawan. Jakarta : Dewan Pers https://id.wikipedia.org/wiki/Profesional diakses 20 Maret 2018 http://www.unpad.ac.id/rubrik/bekerja-profesional-dan-cerdas-menurut-islam diakses 20 Maret 2018 http://dewanpers.or.id/berita/detail/879/Wartawan-Diajak-Tingkatkan-Profesionalitas diakses 20 Maret 2018 http://repositori.uin-alauddin.ac.id/3343/1/Syahwal 